\title{
Breaking the silence through MANTRA: Empowering Tamil MAN survivors of torture and rape
}

\author{
Pearl Fernandes*, Yvette Aiello*
}

\section{Key points of interest}

- Male sexual torture is under reported and under-detected, mainly due to feelings of shame and guilt, and norms that tend to repudiate sexual violence and rape targeting men.

- A combination of group and individual therapy with a group of Tamil asylumseekers in Australia shows promising results. Specialised interventions that integrate exposure therapy can assist clients to feel safe and understood and help them to rediscover their resilience.

\begin{abstract}
Introduction: The prevalence of sexual torture, including rape as a form of torture against men in the context of war and persecution, has been widespread throughout history and across cultures. Despite this, literature examining this highly complex and pervasive problem has only recently begun to emerge.
\end{abstract}

*) Service for the Treatment and Rehabilitation of Torture and Trauma Survivors (STARTTS), New South Wales, Australia
This is partly a reflection of the taboo nature of the topic, which results in lack of disclosure, a poor understanding of the issue, and leads to gaps in effective therapeutic interventions. Objective: This paper aims to provide a reflective narrative on an intervention trialled at the NSW Service for the Treatment and Rehabilitation of Torture and Trauma Survivors (STARTTS). It outlines the therapeutic strategies that were integrated in culturally sensitive ways and the phases and themes that emerged as the men overcame their resistance to speak about their experiences of torture. Results: The combination of group and individual therapy that integrates exposure therapy in a culturally appropriate way can assist clients to revisit their traumatic experiences and 'break their silence' as they heal and recover. Conclusions: When male survivors of sexual torture share and verbalise their past horrors it assists them to make meaning and develop a new, broader perspective, on their experiences. Accompanied by a diminishing sense of shame, and "therapeutic activism," it instils hope and the motivation to assist others in crisis, particularly regarding the issue of male rape.

Keywords: Male sexual torture, specialised group therapy, reflective narrative 


\section{Introduction}

Contemporary discourse on war and conflictrelated sexual torture as a weapon of war does not generally include men. International jurisprudence ignores sexual torture and male rape as instruments of torture against men (Vojdik, 2013). However, sexual torture targeting men is widespread and involves barbaric acts of brutality, including rape, that could imply a loss of manhood, may harm relationships, and can also challenge the stereotype of a man's ability to protect his family and community. As an instrument of terror and repression, sexual torture against men reflects the need to dominate, control and humiliate.

Sexual torture, including rape, is a taboo across cultures and linked with a myriad of myths and beliefs incuding: that men cannot be raped; only homosexual men are raped; and that men can manage the consequences of rape as they are emotionally stronger. Furthermore, men often fear that if they disclose being sexually violated they could be ostracised from their family and community and labelled homosexual, which is often stigmatised and even illegal in many contexts globally (Russell, 2011; Sivakumaran, 2007; Vermeulen, 2011). Thus sexual violence against men tends to be under-reported or not reported and, consequently, male survivors do not receive support, which could perpetuate their suffering.

There are political and legal reasons for non-disclosure. Sexual violence against men was only recently recognised by the UN Security Council in 2013 (Priddy, 2013). Rape is defined as an act perpetrated against women alone in 61 countries, and 37 countries criminalise male rape as homosexuality (Alcorn, 2014). Furthermore, the pathway to seek justice is often retraumatising, ineffective, and a potential barrier to disclosure. This denial and silence that shrouds sexual torture has resulted in a poor understanding of its consequences. Organisations that offer legal, medical and psychological services are not sufficiently trained to recognise indicators and respond appropriately to men who have survived sexual torture.

Findings from a few studies suggest that group interventions have higher efficacy and may be more appropriate when working with people who have experienced sexual torture (Callahan et al., 2004; Herman, 1992). In a recent literature review, only seven studies were found that reported on psychosocial interventions aimed to assist individuals who had been sexually violated in the context of armed conflict (Wietse et al., 2013). Current research suggests that the provision of psychosocial interventions, particularly using culturally adapted interventions, group therapy approaches (Wietse et al., 2013), and elements of exposure therapy (De Jong, Knipscheer, Ford \& Kleber, 2014) are beneficial in addressing the psychological sequelae resulting from sexual violation. Literature supports the use of specialised interventions to address the complexity of trauma responses (Schopper, 2014). However, despite evidence for the efficacy of group work in the treatment of complex trauma and sexual abuse, there is a current scarcity of clinical groups for men who have experienced sexual violence in the context of war.

The extensive incidence of male sexual torture as a weapon of war continues to be overlooked despite reports from the UN and the media indicating that it takes place in war-torn countries such as Sri Lanka, the former Yugoslavia, Rwanda, and the Democratic Republic of Congo. In Sri Lanka it has been reported that Tamil 
men, suspected of being supporters or members of the Liberation Tigers of Tamil Eelam (LTTE), have been systematically tortured and sexually violated by Sri Lankan authorities (Human Rights Watch, 2013; International Truth and Justice Project Sri Lanka, 2015). Due to cultural taboos and fear of reprisal men are not forthcoming in seeking assistance to deal with the consequences of these acts. This could take a toll on their mental health and create overwhelming distress, leading to unprecedented behaviours in the face of additional stress.

One such incident occurred in early in 2014 when a Tamil asylum seeker attempted self-harm in New South Wales (NSW) following a rejection of his claims for protection. An ex-client of STARTTS, from a Tamil background, informed the authors that the motive behind the attempted suicide was the anticipatory fear of sexual torture upon return to Sri Lanka. This client had benefitted from individual treatment for sexual torture at the organisation. He also cautioned that there were other Tamil men in the community in NSW who were likely to follow the example of this young man as they too felt overwhelmed by anticipatory fears. He understood that the sequelae of sexual torture was not easy to cope with and shared his belief that it was STARTTS' moral responsibility to reach out to the Tamil asylum seekers living in the community.

MANTRA, an acronym for 'MAN Torture and Rape', was therefore developed to assist Tamil survivors of sexual torture seeking asylum in Australia. Mantra is a Sanskrit word that translates as 'instrument of the mind' (MAN= mind, TRA= instrument). In addition to stating the nature of the group up front, the acronym also acknowledges the power of self-talk and thought.

\section{Method}

Structure of the group

Clients, referred through community members, were invited to attend individual assessments to ensure readiness for group work. At the assessment it was clarified that reflecting on experiences of torture was an important aim of the group. The inclusion criterion was a willingness to acknowledge that they had experienced torture, including sexual torture. All clients were assured that there would be no pressure to disclose.

Table 1: An overview of the MANTRA groups

\begin{tabular}{|c|c|c|c|c|}
\hline $\begin{array}{l}\text { Group } \\
\text { Number }\end{array}$ & $\begin{array}{l}\text { Age } \\
\text { Range } \\
\text { (years) }\end{array}$ & $\begin{array}{l}\text { No. of Partici- } \\
\text { pants }\end{array}$ & Dates & $\begin{array}{l}\text { Frequency of } \\
\text { sessions }\end{array}$ \\
\hline 1 & $24-49$ & 6 (1 drop out) & July-September 2014 & Weekly \\
\hline 2 & $24-36$ & 6 & October-November 2014 & Twice weekly \\
\hline 3 & $23-33$ & 8 & March-May 2015 & Weekly \\
\hline 4 & $26-48$ & 8 ( 1 drop out) & August-November 2015 & Weekly \\
\hline 5 & $25-38$ & 6 (1 drop out) & $\begin{array}{l}\text { December 2015-February } \\
2016\end{array}$ & Weekly \\
\hline 6 & $24-29$ & 6 (1 drop out) & April-June 2017 & Weekly \\
\hline 7 & $26-40$ & 6 & July-September 2017 & Twice weekly \\
\hline
\end{tabular}


Consent forms were translated into Tamil and noting rights and responsibilities of participants were completed.

The first MANTRA group was held in July 2014. Ten weekly group sessions were facilitated with the assistance of interpreters who were accredited by the Translating and Interpreting Service (TIS). Each session lasted at least 2.5 hours. Table 1 provides an overview of the 7 MANTRA groups that have been facilitated along similar lines.

In total, 46 men took part with 4 dropping out due to reasons linked to a surgery, work pressures, moving interstate, and preference for individual treatment. The majority had not engaged in previous treatment and reported that their shame prevented them from addressing medical issues such as anal bleeding, incontinence, pain, and discharge. A majority were detained on multiple occasions and reported being targeted on suspicion of their allegiance to the LTTE or political parties. However, many were civilians and targeted because of ethnicity. Nearly all reported being unable to complete formal education. The most prevalent occupations were 'fisherman', 'labourer' and 'jeweller'.

\section{Group strategies}

MANTRA integrated multiple, culturally appropriate, strategies to address the complexity of the trauma that the men experienced. The initial group sessions aimed to build trust and assist each participant to create their own 'safe space'. Activities that incorporated movement and a willingness to explore were simultaneously introduced to pave the way for psychoeducation. For example, group games to illustrate the functioning of the brain were introduced. Metaphors and stories were then used to encourage exploration of the past and also to identify and enhance participants' pre-existing strengths, coping, and survival strategies.

Interventions and strategies adopted in the groups to address the multi-level impacts of trauma are summarised below:

- Psycho-education to build understanding of the impact of traumatic experiences on mind and body.

- Culturally appropriate metaphorssuch as 'the white elephant,' 'breaking a coconut,' and 'the elephant in the dark' - were utilised to assist with psycho-education and to enable participants to examine thoughts, feelings, and behaviours.

- Parables and vignettes from cultural texts; Draupadi's attempted sexual assault (Mahabharat), the origins of the SO-HAM and Lord Shiva's churning of the ocean served as additional sources for reflection and self-learning through identification and projection.

- Heroes and cultural icons were remembered as a means of re-connecting with their 'lost' culture and country, and to assist the group to rebuild their shattered sense of self.

- Elements of prayer (chanting) and music were introduced by both participants and facilitators.

- Recollection and processing of traumatic experiences was facilitated through a Narrative Exposure Therapy (NET) framework.

- Visualisation exercises were introduced to assist in identifying and accessing a place of strength, comfort or calm.

- Elements of yoga; 'asana' and 'pranayama' helped facilitate grounding, affect regulation and a mind-body connection.

- The concept of MANTRA helped with exploring the power of self-talk and underlying schema. 
Mantra (as a chant or instrument of the mind) is associated with spirituality. Group discussions often veered towards a spiritual realm, particularly in context of the intimate and brutal nature of sexual torture. The intense sense of helplessness in the face of incomprehensible incidents in many groups made it important to acknowledge the need for a healing power, 'force' or 'spirit' that was referred to as "Shakti."

\section{Individual sessions}

Participants were offered individual sessions to explore and process memories that were particularly challenging. The group sessions may have paved the way for individual sessions as the majority had previously rejected individual counselling. In the individual sessions, participants could also record their testimony which was read back to them until they were satisfied that what was recorded accurately represented their experiences. Testimonies recorded in first person were a way of capturing participant voices. Themes from these testimonies were often mirrored in group sessions.

The number of individual sessions ranged between one and six. As additional time was needed to process painful memories, each individual session lasted at least ninety minutes, with a few taking up to three hours.

\section{Data analysis}

The following data sources were used for analysis:

- Progress notes maintained by both group facilitators.

- Additional notes on reflections and impressions were added from each postsession debrief.

Following the final session, a thematic content analysis of all data was independently conducted by both facilitators, prior to collaborative coding. This was used to identify the stages that the group went through as they explored their past and the dominant themes of their lived experiences over time. Both facilitators also received ongoing regular supervision with a senior clinician at STARTTS. If there was a disagreement in the themes and phases, as they emerged during the sessions, they were discussed to ensure better understanding and achieve a collaborative consensus.

\section{Findings}

Table 2 represents an overview of the group processes and the themes that emerged as the groups progressed. Although it is a challenge to capture this nuanced interplay, the diagram attempts to depict the parallel and overlapping nature of the processes and themes. Hence the perforated arrows that link into each other symbolise group processes and represent the fluid nature of this complex process. Overall, participants tended to initially discuss common themes that they all had witnessed before sharing personal experiences.

\section{Recurrent Themes}

Content analysis of the sessions established the nine recurrent themes captured below:

Widespread destruction: Vivid images linked to the carnage and aftermath of the protracted civil war were recalled and included: frequent shelling and bombing; displacement from a young age; obliteration of homes and neighbourhood; dismembered bodies; and deaths of friends and family.

Fear for family members: Participants consistently voiced concerns for the safety of their families in Sri Lanka. Underlying this was guilt. They were safe but their loved ones continued to live precariously, be 
Table 2: A summary of emergent themes and group processes

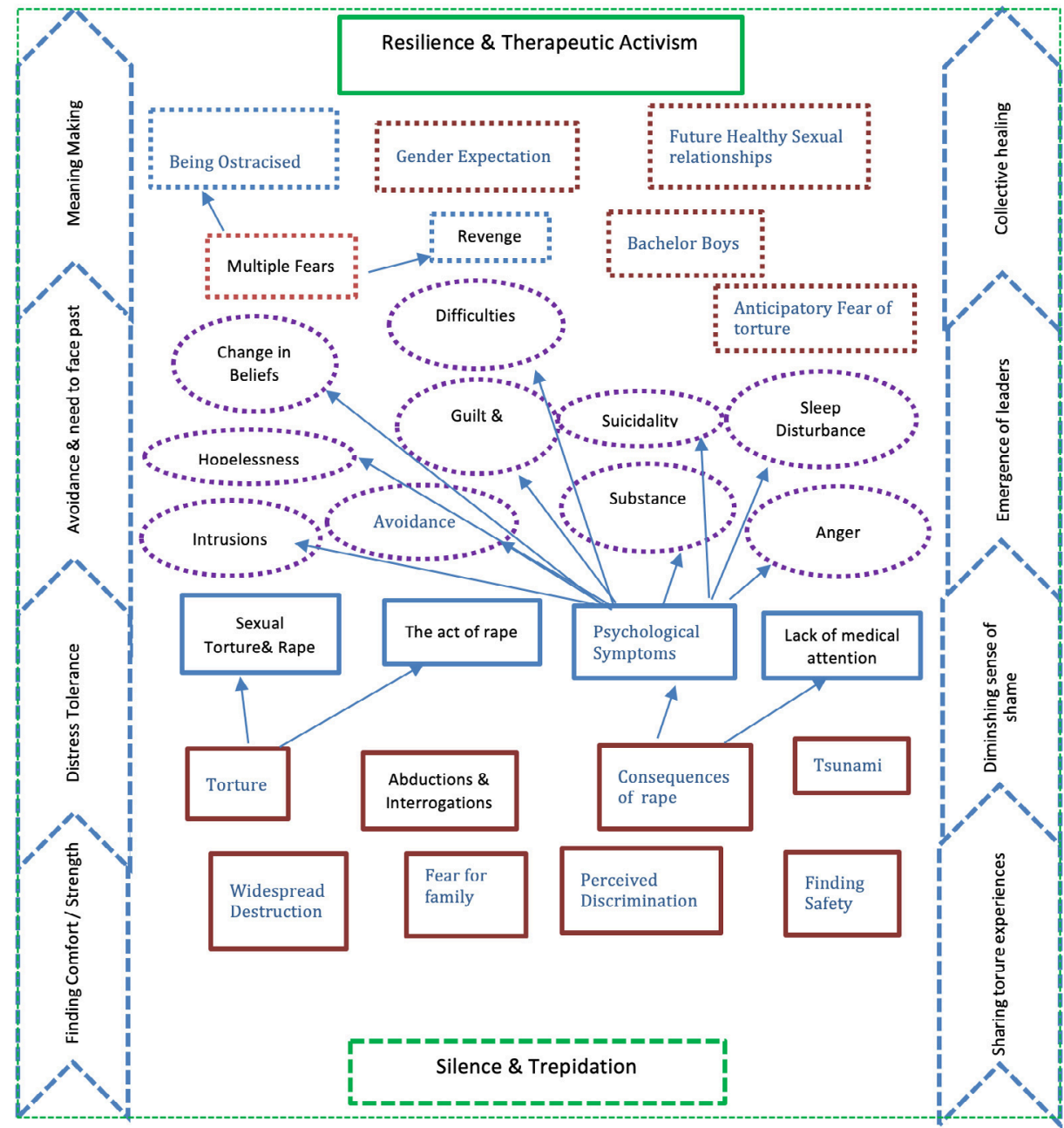

Key:

Major Themes across all groups $=$

Group Processes =

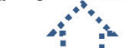

Sub- Themes linked to major themes $=$

Themes in some groups =

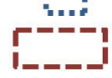

When group commenced $=$

エேー・

Psychological Symptoms =

Sub-themes linked to these themes $=\mid$

Towards the end $=$ 
harassed, interrogated and received ongoing threats often because of them.

Increased sensitivity to perceived discrimination: Continuous and ongoing discrimination, persecution and racism endured since childhood because of their Tamil ethnicity, was remembered. Participants vented their frustration that the Department of Immigration and Border Protection did not understand and acknowledge the communal trauma, grief, and loss of their ethnic group. They drew parallels between their experience seeking asylum in Australia and persecution in Sri Lanka. The perceived lack of transparency and consistency in the asylum process in Australia was reminiscent of the actions of authorities in Sri Lanka. Further, many commented on their ongoing treatment as a "second-class minority" in Australia despite being in a democratic country where they had hoped to find respect and equality. The prolonged uncertainty and the refugee determination process was perceived as a form of psychological torture, as illustrated through the following quotations: "There (in Sri Lanka) they have physical torture. But here they have psychological torture. It's the same thing. The government is doing the same thing, torturing asylum seekers" and "The Australian government is telling citizens to not go to Sri Lanka as it is too risky but they are saying it is O.K. for us to go back to Sri Lanka."

Others described their feelings as "roasting in the pan"; "living in Hell"; and "pain you can't describe." The men felt dismissed and ignored by society at large and cited examples of recent news events and other conflicts as evidence of disinterest and discrimination against the plight of the Tamils in Sri Lanka:

"In our country many people were killed and no one did anything. The world changed because of one picture of a Syrian refugee child"; "I feel angry at the world. A plane crashed and 150 people died and the whole world talked about it but a nation came today and killed thousands of Tamils and no one cares. I am very hurt as I watched my sister die in front of my own eyes." Hence participants believed that the Tamil community were discriminated against in Sri Lanka, Australia, and by the international community.

Finding safety in Australia: In all groups the distress linked to an uncertain future in Australia was unmistakable. Nevertheless, participants unequivocally expressed gratitude as they felt safe in Australia, despite separation from family and multiple losses. One man remarked, "I can't see the happiness I have had here anywhere else." The men shared their mixed emotions but they felt safe as their lives were not in danger in Australia and believed that they could find the courage to endure the ongoing "psychological torture" they were being subjected to rather than risk possible future torture and certain death if they were to return. This feeling was supported by information related to the detention of Tamil asylums seekers upon their return to Sri Lanka.

Tsunami: The impact of the tsunami that struck Sri Lanka on $26^{\text {th }}$ December 2004 and the horror, devastation and loss that followed this natural disaster was highlighted. A few explained that talking about the tsunami was less frightening as it was a natural disaster and "dealt with" together (Tamil and Sinhalese) by the community.

Abductions $\mathcal{E}$ interrogations: A majority reported that they were abducted by the Sri Lankan Army (SLA). A few also had been forcibly "taken" by the LTTE when young but 
tended to downplay this as, in hindsight, they believed it was for the cause of "Tamil Elam."

Being tortured: The majority reported that, when abducted, they were verbally threatened, abused, shoved, slapped, kicked, and often hit with rifle butts. The interrogation rooms were described as intimidating. Torture instruments, overpowering putrid smells and blood stained walls were clearly visible and evident. When interrogated, they were brutally assaulted with batons, Palmyra branches, rods, burnt with cigarettes, had fingernails pulled out, threatened with guns held to their head, and/or asphyxiated. Their heads being forcibly immersed in polythene bags doused in petrol or chilli powder was also reported. Suspension by the ankles or wrists, beating of soles of the feet and being held in overcrowded cells or in solitary confinement were other methods described. Many recounted being exposed to sounds and sights of others being tortured. A few also explained how there were injected with substances and forced to do labour jobs. Nearly all reported being given very little or no food to eat.

Sexual torture and rape: Sexual torture was mentioned with trepidation. The impact and widespread use of rape as an instrument of torture was spoken about in all groups, almost as preparation for the men to focus on their own experiences. Notorious locations where sexual torture including rape comprised the "Fourth Floor" CID headquarters in Colombo, Omanthai Camp, Welikade prison and Busa camp.

The actual act: When discussing enduring multiple forms of sexual torture, participants agreed that "in many cultures whenever there is war the second weapon is sexual assault. It is established and true that in Sri Lanka it is abundant." The sexual torture predominantly occurred in police stations, prisons or SLA camps.

Across all groups, the gradual progression of torture was mentioned as participants advised that intimidation and threats would progress to beating, mutilation and eventually sexual torture and rape. All reported being stripped naked during interrogation and unanimously agreed that "if you are not mentally strong you cannot survive as the pain and fear is so intense that you can have a heart attack."

Many participants were suspended from their wrists or ankles with ropes/ chains or made to lie face down on a bench/ table when naked. Squeezing testicles and beating the penis with sticks or rods was commonplace. Men also disclosed being penetrated anally, being forced to have oral sex where perpetrators ejaculated in their mouths or urinated on them. Some men disclosed that objects such as plastic pipes were shoved into their anus and a barbed wire inserted through the pipe with the intent of causing internal damage.

\section{Aftermath $\mathcal{G}$ the Consequences of Rape}

Lack of medical attention: Three themes are presented here in relation to 'the aftermath and consequences of rape' theme, the latter of which has multiple further sub-themes. Participants recalled being denied appropriate medical treatment after being tortured. This resulted in ongoing physical health concerns including chronic pain, suspected urinary tract infections, and sexual dysfunction.

Longer lasting emotional scars: There was a general consensus that the psychological impact of being tortured was devastating, it "mentally killed" them and was more severe than the physical scars. They all agreed that "the psychological torture does not heal. The other 
level is physical which will also affect the mind but the main purpose of the torture is psychological."

Psychological symptoms: The reported symptoms could be categorised under the overarching labels of Post-Traumatic Stress Disorder (PTSD), Depression and Anxiety and included:

- Intrusive memories: The most distressing examples expressed sentiments such as "wherever we go all the tortures are in our past. On Sundays I catch the train and the thoughts come back. I don't have enough strength to control my mind. Even while sitting here I am thinking of the torture." Managing intrusive memories was difficult at night when they felt most vulnerable: "when I go to sleep all these things come like a movie"; "I can feel the pain in the dream."

- Avoidance and dissociation: This was also common and helped the men cope with overwhelming worry and pain: "sometimes when the pain gets so bad I go blank. I can't see anything and I don't know where I am or what's happening."

- Substance abuse: Groups shared that they had friends who turned to alcohol and drugs as a means of blocking pain and intrusive memories.

- Anger and sleep difficulties: Common indicators of alteration in arousal and reactivity were reflected in statements such as "when I get angry I cannot control my anger. I go back to what happened."

- Suicidal thoughts: "My mind is always asking why we are living?"; "I think it is better to be dead as I would be released from the pain" and "there is no meaning in life"; "If it becomes known (that I was raped) then I would need to suicide as I can't face society."

- Difficulties with affect regulation:

This was frequently mentioned and explained as "our thinking brain is not working... every day we have a power cut. A short circuit when the body shuts down."

- Alteration in self-beliefs, selfesteem, loss of manhood: Participants confided that they began to doubt their identity with thoughts such as "I have no strength"; "I am incapacitated."

- Deep feelings of guilt and shame: "I am at fault"; "I am not fully responsible but maybe I did something to bring it on"; "I am lower in society" and "I am not as good as someone else."

- Hopelessness: This was prevalent in all groups. As a poignant example, one man did a self-portrait as a man sitting on a chair in the rain with his umbrella shut and closed next to him. He explained, "I am not taking any caution to stop getting wet," and "can't get any solution and always more problems; it is hard to untangle like this."

- Change in belief system: Many also reported questioning their religious beliefs. For example, asking why God had allowed them to be hurt in such a manner and another jokingly stated, "God got on the earlier boat."

- Difficulties with trust: In all groups the challenge of disclosure with friends or family was mentioned and linked to the culture of disbelief and often expressed as: "they don't give any written documents about this (sexual torture) so there is no way to prove it"; "some problems we tell others and they suspect whether it is true or not." The consensus was "only if they (the wider community) see with their own eyes will they believe." This fear of not being believed extended to the Department of Immigration and the international community.

\section{Other Themes}

Five further sub-themes are grouped under 'other themes.' 
Multiple Fears: Participants feared being blamed and ostracised by their community if they disclosed and explained that: "society won't accept him if he was sexually tortured"; "they would look at the person in a funny way, laugh at the person. His wife or children may leave him as they will believe that he can't protect himself so he can't protect his family." They shared that even if sexual torture was not disclosed, they would still be shamed by society as sexual torture was known to be rampant in Sri Lankan prisons and army camps and said, "Whoever was taken to prison will be treated differently by the community. They all know what happened there and the community will tease and degrade us." In addition, participants shared a premonition that members of their family had been, or could be, targeted in "revenge attacks" when authorities were unable to find them.

Gender expectations: The expectation that "men are meant to just tolerate it, to be brave and not talk about it" was often voiced as the men felt that women had the freedom to "cry and let it out but the men will hold it all in."

Anticipatory fear of torture: The groups universally expressed that being sexually tortured was frightening and the possibility of this recurring terrified them more. One man explained that "the physical pain is less than the mental pain"; "the torture was O.K. but what was worse was the fear of the next time they would take me." The men shared that their fear was so intense that they "would rather die than go through the same torture" and when they thought of this possibility they "think of ways to suicide." This fear of being tortured sexually again was overwhelming and underpinned the intense fear of being returned to Sri Lanka.
Bachelor Boys: Men in the groups, who were in their late 20s and 30s and had been forced to flee their homes, shared their disappointment that culturally determined expectations and milestones such as marriage, parenthood, and an established career were disrupted. They often referred to themselves as "bachelor boys" and one respondent stated, "when...they often said: "when I see the clock I am thinking I am going to waste. We forget our ambition and aims when we come here. We don't even know the next step." This was compounded by visa restrictions that limited their ability to pursue studies and find suitable employment.

Future healthy sexual encounters/relationships:

Members of the group who were in relationships spoke about sexual acts triggering or confronting them and remarked, "I think I could not have sex with my wife because of what he did to me. I am not sure if I will be able to have sex with a woman because of this." Some members also reported ongoing sexual dysfunction following sexual torture. Some could not differentiate or understand the difference between sexual health and sexual dysfunction.

\section{Group Processes}

The following section outlines processes observed across groups over the course of ten sessions by theme.

Silence and trepidation: The initial phase characterised by trepidation, reflected by silence, tense body language, and restlessness. Some clients had difficulty being seated in the room for the duration of the session. Many could not participate in group activities and discussions and explained, "we do not talk about our internal injuries."

Finding comfort and strength: Identifying a place of comfort or strength was not easy and 
participants acknowledged and verbalised the struggle to think of or even imagine such a place, reflecting their own feelings of vulnerability and discomfort. One participant shared that he "went all the way back to my mother's womb to try and find a place of strength." Sharing this feeling of disquiet may have released some tension and, as the session and groups progressed, participants gradually reflected on their increasing feelings of comfort and strength, not only within the group but also within themselves.

\section{Distress tolerance and sharing life} experiences: Reconnecting with themselves, participants began to develop trust in each other and the therapeutic process. This correlated with an increase in their ability to tolerate the challenge of exploring their past. Experiences were reconnoitered-first the more commonly known incidents then gradually those that were more intimate. This generally involved beginning to speak about incidents witnessed by the community, before touching on those experienced by family, and finally themselves.

\section{Collective healing: emergence of leaders and} empathy: In every group, a few would take the lead and begin to reflect and process their complex experiences. As they began to better understand their experiences, they then began to actively support and encourage other participants to think about the past.

As participants verbalised their collective traumatic experiences, they gradually experienced relief (catharsis). They simultaneously enjoyed the reverie and benefits of being understood and validated by others. A few participants acknowledging this support would say, "If we are confused we can share and make it clear with the group" and "some of the stories the group told I had never heard about, it helped me to understand my own experiences."

Interplay between avoidance and need to face the past: emerging hope: Initially, not all members had the courage to share initially, which was respected. However, realising the benefits from the example of others, and a possible re-interpretation of their own experience, they eventually broke their silence.

The men began to collectively explore experiences they had not shared with anyone before or were previously too afraid to think about. They were surprised to remember incidents they had not thought of in a long time and hence not mentioned in their initial timelines, such as important childhood events including displacement, loss of siblings, and the deaths of significant family members. Recalling these memories gave them a new perspective, release, and hope. This is captured by the following quotation: "Initially I was hesitant to share as I felt I shouldn't burden others. When I did share I felt unburdened and I realised that others had also been through torture and some worse than mine."

Some participants began to spontaneously share their memories, as if they could not contain their recollections. Many often did not want to stop talking and would often linger after the end of the session with a need to continue. Several sessions were extended to ensure closure and grounding.

Diminishing sense of shame: By continuing to share painful and "shameful" experiences, a gradual habituation occurred. This served to reduce feelings of shame and anxiety and dampen the intensity of their emotional responses.

Meaning making: Participants came to understand that they had been primarily 
targeted due to their ethnicity as Tamils rather than any personal attribute. The understanding that violence had been perpetrated against them for reasons beyond their control, and that it was not their fault, also helped to reduce their sense of shame. They simultaneously began to recognise and acknowledge their own acts of courage in the midst of the horror of the experience as conveyed here: "It is because we are born Tamil that we have been targeted. The Tamils are a weak race, but listening to what others have said I began to understand what we have been through ... and gave me the courage to talk about myself."

Shift from silence to resilience and therapeutic activism: As the groups progressed, participants began to affirm each other and realise that their core beings had not changed. They shared the sentiment that "I do not want anyone else to experience what I have been through-beaten and tortured. I like to share so others can know how to be careful." Some participants expressed a need to be involved in assisting other refugee communities in crisis, particularly in advocacy about the issue of male rape. This could be understood as therapeutic activism.

\section{Evaluation}

Evaluating outcomes related to an intervention linked to sexual torture is a challenge. The reluctance to disclose and deliberate the impact of an intimate experience like sexual torture makes it difficult to administer standardised evaluation techniques. Hence attendance, self-reports and clinical observations were relied on to aid reflections on MANTRA.

\section{Attendance rates}

The low dropout rate ( 4 out of 48 persons) suggests that the men who partook in
MANTRA were committed to the program and found it useful.

\section{Self-reports}

Positive self-reports from participants indicate the benefits of MANTRA with nearly all reporting that they felt more confident about themselves and comfortable to speak about their traumatic memories.

Eloquently describing this shift, one participant shared:

"Now I can talk in group but I didn't know how to talk about my problems before. First I needed the opportunity and the confidence. My brain said don't tell anything and my mind said to tell. There is a challenge between these two powers. I feel like you were teaching a small child how to speak and finally we have started to talk."

Others shared this sentiment and also reflected that following the group sessions they experienced decreased anxiety about the refugee determination process: "Since attending sessions I have become confident to talk about my problems. I can't say I would be able to say all this to Immigration before."

They also reported a reduction in symptoms as a consequence of having the opportunity to share and reflect on each other's experiences. Participants shared sentiments such as, "I have less heaviness in my chest"; "This (group experience) helped me put my memories in order"; "We have fears but the group gave us a chance to leave them here and go without our fears" and "I feel freed."

Others reported about benefitting from the opportunity to be heard amongst peers as this provided a space for understanding and validation: "When coming here at first we didn't know what to do. I relieved myself by coming here. I met all these people and my behaviour has changed."; "We feel relieved that at least seven or ten people listened to our story"; "I learnt that there are people who care 
about us" and "Initially I felt hesitant to share as I felt I shouldn't burden others. When I did share I felt unburdened and I realised that others had also been through torture and some worse than mine."

Finally, they also reported increased hope and positive feelings towards the future: "There are a lot of problems in my head. They are still in my head and that is a problem for me but I have the feeling that I want to live." The above was also reflected in reports of many men who secured employment and were beginning to make plans for their future.

Overall, participants reported greater ease in tackling daily challenges and often used humour in group activities and discussions in a manner that suggested that it was more than an avenue to discharge tension. Hence when reflecting on the groups, many related that it was the laughter they most remembered. This was in contrast to their presentation in initial sessions and was indicative of the joy and comfort they experienced in sharing and connecting with each other.

Initially, there had been embarrassment about attendance at a mental health service and their membership of a group for male survivors of sexual torture. However, by the end of the group sessions, there was a sense of trust and pride as participants did not hesitate to identify themselves as MANTRA members. This extended to requests for reunions and for an ongoing MANTRA group. Many men also suggested that we needed to establish a group for women as they believed women from their community had endured sexual violence. A few referred their wives to the group for women.

\section{Clinician Observations}

Clinical observations evidenced cohesion in the groups as social capital was built between participants. As participants grew in confidence to express themselves, it was also observed in their body language through improved eye contact and posture. Therefore, it was observed that a few men appeared noticeably younger during follow-up visits after the end of the group sessions.

For reasons of simplicity, a possible way to describe observed changes in participants is by classifying them into four broad and fluid categories based on their functioning, expectations related to therapeutic outcomes, and their relative therapeutic trajectories.

\section{Stoic: Participants with this profile} presented as thoughtful and insightful. Appreciative of the support and direction being offered, they took on leadership roles in the group. They were knowledgeable about the "cause" related to the civil war as they were either former LTTE members or had close family members who were martyred for this "cause." They believed in testimony being a pathway to justice. They appeared to benefit the most as they were actively seeking and expecting improvements in their mental health. Their resilience buoyed them towards therapeutic activism which influenced their choice to become involved in advocacy related to sexual torture.

\section{Skeptics: Participants who were verbose} and could easily take the group away from the issue being discussed were more likely to belong to this group. They appeared preoccupied with their own difficulties. They faced family separations, perceived injustice by the government, and were finding it more difficult to cope. Needing more time to build trust, they accepted suggestions or strategies to improve their mental health only after questioning and deliberation. Writing their testimonies may have been a possible route 
to strengthen their claim for protection. Although hoping for change, initially they were not convinced that they could share their experiences or really get better. Towards the end they felt they had enough confidence to share their personal experiences with family and friends.

\section{Embattled survivors: Participants who were} embroiled in their sufferings and may have relied on their predicament in efforts to distract from their past or justify their avoidance could be conceptualised as 'embattled survivors'. Unsure of what to expect, they needed time to build trust. They were on the lookout for 'quick fixes' and could not understand the longer-term benefits of therapeutic strategies. Nevertheless, they preferred to be given directions and readily placed the clinicians as experts, without genuinely believing their circumstances could shift. They were not coping adequately and displayed a tendency to be more evasive and silent. They did not wish to stand out and tended to go along with what the dominant majority expressed. They reported a reluctance to share their experiences with others unless they had no options.

\section{Curious drifters: This participant profile} refers to those who may have been 'accidental' referrals, hopeful to seek support with their claims for protection. They did not have much insight into their issues and were coping more effectively and defined torture experiences in a more subjective manner. Their attendance pattern was irregular and they were noncommittal about their willingness to share their past with family and friends.

\section{Discussion}

One of the common threads that link survivors of sexual torture and rape, even though they could be from diverse backgrounds, is the silence or nondisclosure following these acts. A reluctance to talk about these experiences was universal in the initial group sessions. However, all participants in MANTRA expressed a desire for change and the need to get better. From this starting point, encouraging and guiding disclosure assisted the group to become more aware of not only their feelings but their coping strategies and hidden strengths that were influenced by their life experiences, including the wisdom inherent in their cultural heritage. Assisting survivors to access and make meaning of their memoriesbeing dehumanised, humiliated and yet surviving - was therefore empowering.

Perceptions and reactions to sexual torture cannot be fully understood without due consideration to the cultural milieu that defines concepts of manhood and culpability. Myths that men are stronger and better able to deal with sexual torture or notions that it only occurs to women are challenged by the narratives of men in MANTRA. Unfortunately, very few perpetrators of sexual violence are prosecuted. This impunity is one of the reasons why sexual violence is so rampant to date and widely used as an illicit weapon in conflict to repress and instil fear in both women and men. It is also one of the reasons that spark anticipatory fear as these acts can and often do re-occur.

There is an increasing need to identify and document incidents of sexual torture and therapeutic interventions to assist survivors of sexual torture as there is a growing population at risk that still need urgent assistance and interventions. In spite of this need, there is a dearth of literature and there are limited campaigns that raise awareness about sexual violence or make 
targeted, specialised, interventions that address war-related sexual violence.

Given the complexity of the impact and circumstance related to organised sexual violence, there is a need for interventions that target shame and secrecy and incorporate strategies across multiple levels-not only the individual but also family, community, national, and international levels.

\section{Limitations}

This paper is a reflection of an emergent practice that developed in response to an urgent request for assistance from the Tamil community in NSW, Australia. The sample was largely self-selected as participants were predominantly referred through word of mouth. The authors did not intend this to be a research project and therefore acknowledge the importance of having a purposeful random sampling strategy to extend conclusions from this project across cultural groups. However, the basic principles of establishing safety and relying on 'group wisdom' to instil hope and the courage to explore the horrors of the past could be beneficial to survivors of any cultural background.

The inherent bias in relying on detailed notes in the analysis is also acknowledged. Attempts were, however, made to address this issue in regular consultations with a senior clinician that were designed as part of good practice to ensure responsiveness to client and service needs.

Participants own voices are reflected in their testimonies and a systematic analysis could potentially be conducted in a subsequent study; however, this is beyond the scope of this paper. The lessons from this project could also be carried forward in future, through a more participatory style research project. However, given the silence that surrounds male rape, recruiting participants to this group could be challenging.

\section{Conclusion and recommendations}

Sexual torture including rape continues to be used as a weapon targeting men in wartorn countries. The International Truth and Justice Project Sri Lanka (2015) and Human Rights Watch (2013) have reported the incidence of rape in Sri Lanka. MANTRA evolved to address an urgent request from an asylum seeker from the Tamil community in Australia who was an ex-client. His request was for STARTTS to address the complex needs of other members from his community, who had survived sexual torture in the context of their anticipatory fear of forced repatriation and had an inability to think and talk about their experiences.

MANTRA involved a complex sequence of interventions and responses that are not easily explained by a simplistic theory of change. MANTRA confirmed that sexual torture has impacts across multiple domains of functioning. However, creating the space to share these horrors in a group setting can assist survivors to process and cope with them. The effectiveness of group therapy and culturally sensitive strategies adapted in MANTRA is consistent with current research (Wietse et al., 2013). The results obtained in MANTRA suggest that a combination of group and individual interventions are a valuable means of empowering survivors to revisit the past and address some of the social impacts of sexual torture. This is consistent with current literature from the relatively few studies conducted to date (Callahan, Price \& Hilsenroth, 2004; Herman, 1992).

MANTRA identified certain areas that need further development. This includes the development of a robust screening tool to identify survivors of 
sexual torture to maximise the benefits of group interventions. A screening tool could assist to identify survivors and encourage them to think and process the past as a pathway to healing. The importance of offering multi-level interventions which not only target the individual, but also the family and community systems in which they operate cannot be understated. Furthermore, it highlights the importance of offering sex therapy as an important component of survivors' recovery, to address sexual difficulties which could result from sexual torture. Finally, the need for a more comprehensive evidence-based research is acknowledged to assist male survivors of sexual torture.

\section{References}

Alcorn, T. (2014). Responding to sexual violence in armed conflict. The Lancet, 383(9934), 2034-2037. https://doi.org/10.1016/S01406736(14)60970-3

De Jong, K., Knipscheer, J.W., Ford, N. \& Kleber, R.J. (2014). The efficacy of psychosocial interventions for adults in the contexts of ongoing man-made violence: A systematic review. Health, 6, 504-516.

Callahan, K., Price, J., Hilsenroth, M. (2004). A review of interpersonal-psychodynamic group psychotherapy outcomes for adult survivors of childhood sexual abuse. International fournal of Group Psychotherapy, 54(4),491-519. http://dx.doi. org/10.1521/ijgp.54.4.491.42770

Herman, J. L. (1992). Trauma and recovery. The Aftermath of Violence - from Domestic Abuse to Political Terror. New York, NY: Basic Books. https://doi. org/10.1111/j.1471-6402.1994.tb00301.x

Human Rights Watch (HRW). 2013. We Will Teach You A Lesson. Sexual Violence against Tamils by Sri Lankan Security Forces. Online: https://www.hrw. org/report/2013/02/26/we-will-teach-you-lesson/ sexualviolence-against-tamils-sri-lankan-securityforces [20.10.2016]

International Truth and Justice Project Sri Lanka. 2015. A Still Unfinished War: Sri Lanka's Survivors of Torture and Sexual Violence 2009-2015. July 2015. Online: http://www.itjpsl.com/assets/stoptorture_report_v4_online.pdf [14.11.2016]

Priddy, A. (2013). Sexual violence against men and boys in armed conflict. In The War Report. Armed Conflict in 2013.
Russell, W. (2011). Care and Support of Male Survivors of Conflict-Related Sexual Violence. Sexual Violence Research Initiative Briefing Paper.

Schopper, D. (2014). Responding to the needs of survivors of sexual violence: do we know what works? International review of the Red Cross, 96(864), 585-600. Doi: 10.1017/ S1816383114000460

Sivakumaran, S. (2007). Sexual violence against men in armed conflict. The European fournal of International Law, 18(2), 253-276. Doi: 10.1093/ ejil/chm013

Vermeulen, M. (2011). Hidden victims: The story of sexual violence against men in armed conflict. Retrieved from http://www.e-ir.info/2011/09/04/ hidden-victims-the-story-of-sexual-violenceagainst-men-in-armed-conflict/

Vojdik, V. (2013). Sexual violence against men and women in war: A masculinities approach. Nevada Law fournal, Forthcoming; University of Tennessee Legal Studies Research Paper No. 217. http:// dx.doi.org/10.2139/ssrn.2271222

Wietse, A., Stavrou, V., Greene, M., Mergenthaler, C., van Ommeren, M. \& Moreno, C. (2013). Sexual and gender based violence in areas of armed aonflict: A systematic review of mental health and psychosocial support interventions. Conflict and Health, 7(16). Doi: 10.1186/17521505-7-16 